\title{
Plant isoflavones can affect accumulation and impact of silver and titania nanoparticles on ovarian cells
}

\author{
Alexander V. Sirotkin ${ }^{1}$, Richard Alexa ${ }^{1}$, Aneta Stochmalova ${ }^{1}$, Sona Scsukova ${ }^{2}$ \\ ${ }^{1}$ Constantine the Philosopher University in Nitra, Nitra, Slovak Republic; ${ }^{2}$ Institute of Experimental Endocrinology, Bio- \\ medical Research Center, Slovak Academy of Sciences, Bratislava, Slovak Republic \\ E-mail: asirotkin@ukf.sk
}

Objectives. The application of nanoparticles is experiencing a rapid growth, but it faces a problem of their toxicity, especially adverse effects on female reproduction. Food and medicinal plants and their isoflavones can be protectors against environmental stressors, but their ability to abate the adverse effects of nanoparticles has not been studied yet. In the present study, we examined the effect of silver (AgNPs) and titanium dioxide (titania, TiO2NPs) nanoparticles alone or in combination with plant phytoestrogens/antioxidants (resveratrol, diosgenin, and quercetin) on accumulation of nanoparticles, and progesterone release by cultured porcine ovarian granulosa cells.

Methods. Porcine granulosa cells were incubated in the presence of AgNPs or TiO2NPs (0.1, , 10 or $100 \mu \mathrm{g} / \mathrm{ml})$ alone or in combination with resveratrol, diosgenin or quercetin $(10 \mu \mathrm{g} / \mathrm{ml})$ for $48 \mathrm{~h}$. The accumulation of tested nanoparticles by granulosa cells was assessed under light microscope. Progesterone concentration in culture media was measured by ELISA kit.

Results. Cells accumulated both AgNPs and TiO2NPs in a dose-dependent manner. AgNPs, but not TiO2NPs, at highest dose $(100 \mu \mathrm{g} / \mathrm{ml})$ resulted in a destruction of cell monolayer. Both $\mathrm{Ag}$ $\mathrm{NPs}$ and TiO2NPs reduced progesterone release. Resveratrol, diosgenin, and quercetin promoted accumulation of both AgNPs and TiO2NPs in ovarian cells and inhibited the progesterone output. Furthermore, resveratrol and diosgenin, but not quercetin, prevented the suppressive action of both AgNPs, and TiO2NPs on progesterone release.

Conclusions. These observations (1) demonstrate accumulation of AgNPs and TiO2NPs in ovarian cells, (2) confirm the toxic impact of AgNPs, and TiO2NPs on these cells, (3) confirm the inhibitory effects of plant polyphenols/phytoestrogens on ovarian steroidogenesis, (4) show the ability of these isoflavones to increase the accumulation of AgNPs and TiO2NPs, and (5) show their ability to reduce the suppressive effect of AgNPs and TiO2NPs on ovarian progesterone release. The suppressive effect of AgNPs and TiO2NPs on ovarian functions should be taken into account by their exposition. However, these adverse effects could be mitigated by some plant isoflavones.

Key words: nanoparticles, ovary, progesterone, resveratrol, diosgenin, quercetin

The application of metal nanoparticles for production of a number of goods from catalysts, surfactants and medical devices to fertilizers, food additives, pharmaceuticals, and cosmetics is rapidly growing (Mikhailov and Mikhailova 2019; BaranowskaWojcik et al. 2020). Silver nanoparticles (AgNPs) and titanium dioxide nanoparticles (TiO2NPs), due to their antibacterial, antiviral, anti-inflammatory, and anti-cancer properties, as well as the ability to be drug carriers, are widely used in the modern medicine (Grande and Tucci 2016; De Matteis et al. 2018; Mikhailov and Mikhailova 2019; Baranowska-Wojcik

Corresponding author: prof. Dr. Alexander V. Sirotkin, PhD., DrSc., Department of Zoology and Anthropology, Constantine the Philosopher University in Nitra, Tr. A. Hlinku 1, 94974 Nitra, Slovak Republic; e-mail: asirotkin@ukf.sk. 
et al. 2020). In animal production, these nanoparticles are useful for nutrient delivery, promotion of animal growth, increase of meat, milk and egg quality, purification, cryopreservation, and increase of the sperm quality, transgenesis as well as an alternative to antibiotics against antibiotic-resistant bacteria (Hill and Li 2017).

However, there is increased evidence of toxic effects of AgNPs and TiO2NPs on non-reproductive (Grande and Tucci 2016; Flores-Lopez et al. 2019) and reproductive (Brohi et al. 2017) systems, whilst female reproductive organs are particularly vulnerable to nanoparticle toxicity (Brohi et al. 2017). AgNPs promoted expression of apoptosis-related genes (Kim et al. 2004; Gao et al. 2012) and induced loss of germ cells and apoptosis in mouse ovarian follicular cells (Han et al. 2016). TiO2NPs expressed cytotoxic effect on cultured hamster ovarian cells (Di Virgilio et al. 2010). TiO2NPs exposure resulted in TiO2NPs accumulation in the ovary (Gao et al. 2012; Zhao et al. 2013), decrease in ovarian weight (Zhao et al. 2013), reduction in ovarian follicular survival, follicles damage, inhibition in oocyte maturation (Hou et al. 2009), premature ovarian failure (Hong and Wang 2018), induction of ovarian follicular atresia, and decrease in fertility and pregnancy rate (Gao et al. 2012; Zhao et al. 2013). These changes were associated with alterations in expression of genes regulating ovarian steroidogenesis, cell proliferation, apoptosis, and oxidative stress (Gao et al. 2012; Zhao et al. 2013), reduction in production of ovarian progesterone, estradiol, insulin-like growth factor 1, and other hormones and growth factors promoting ovarian functions as well as in luteinizing hormone (LH) receptors (Zhao et al. 2013; Hong and Wang 2018). These reports have suggested toxic effects of both AgNPs and TiO2NPs on female ovarian functions that can be induced by suppression of output of ovarian hormones - promoters of ovarian cell proliferation and suppressors of their apoptosis (Sirotkin 2014). On the other hand, it remains to be established, whether AgNPs and TiO2NPs can be accumulated in ovarian cells, how they can affect the ovarian cells in non-rodent species, and how their toxic effects could be prevented.

There is an urgent need to develop strategies to prevent or mitigate the reproductive toxicity of metal nanoparticles. Treatment with plant flavonoids, which are natural adaptogens, antioxidants, and phytoestrogens (Sirotkin and Harrath 2014; Rietjens et al. 2017), can be a simple, natural, and cost-effective protective strategy against toxic influence of nanoparticles.
Resveratrol (3,5,4'-trihydroxy-trans-stilbene), being not toxic itself (Nawaz et al. 2017), can be accumulated in serum and ovarian follicular fluid (Bodis et al. 2019), and ameliorate the adverse effect of chromium (Banu et al. 2016), toxic plastic plasticizer vinylcyclohexene diepoxide (Ozatik et al. 2020), fungicide mancozeb (Liu et al. 2017), ionizing irradiation (Said et al. 2016), and chemotherapy (Said et al. 2019; Wu et al. 2019) on ovarian functions.

Other plant molecule, steroidal saponin diosgenin (diosgenyl 2,4-di-O- $\alpha$-L-rhamnopyranosyl- $\beta$-Dglucopyranoside) has cytotoxic properties (Podolak et al. 2010), but it can stimulate ovarian cell functions (Sirotkin et al. 2019) and prevent the adverse effect of aging on ovarian functions (Zhang et al. 2019).

The plant flavonoid quercetin (3,3',4',5,7-pentahydroxy-flavone) can suppress ovarian functions both in vivo (Beazley and Nurminskaya 2016) and in vitro (Tarko et al. 2018, 2019), but it can mitigate the toxic effects of chemotherapeutical agents (Li et al. 2014; Jahan et al. 2018), xylene (Tarko et al. 2018), but not of benzene (Tarko et al. 2019) on ovarian cells.

Therefore, the plant isoflavones resveratrol, diosgenin, and quercetin can affect basic ovarian functions and protect them from the adverse effects of some toxic molecules. Nevertheless, their ability to abate the toxic effects of metal nanoparticles has not been examined yet. In the present study, we examined (1) whether AgNPs and TiO2NPs can accumulate in the ovarian cells and affect their functions (creation of monolayer and release of progesterone, the key marker and regulator of ovarian functions (Sirotkin 2014), (2) whether plant flavonoids resveratrol, diosgenin, and quercetin can affect these functions, (3) whether these plant flavonoids can prevent the toxic AgNPs and TiO2NPs effects, and (4) whether this prevention could be due to changes in AgNPs and TiO2NPs uptake by ovarian cells. For this purpose, we examined the effects of AgNPs and TiO2NPs alone or in combination with plant polyphenols/phytoestrogens resveratrol, diosgenin, and quercetin on accumulation of AgNPs and TiO2NPs and progesterone release by cultured porcine ovarian granulosa cells.

\section{Materials and methods}

Preparation and characterization of nanoparticles. Fifty milligrams of silver nanopowder $(<150 \mathrm{~nm}$ particle size, $99 \%$ trace metal basis, CAS No. $7440-$ 22-4, Sigma-Aldrich, St. Louis, USA) or titanium (IV) dioxide nanopowder [mixture of rutile and anatase, $<100 \mathrm{~nm}$ (BET), 99.5\% trace metal basis, CAS No. 
13463-67-7, Sigma-Aldrich, St. Louis, USA] was suspended in $10 \mathrm{ml}$ of complete cell culture medium in a sterile glass conic flask and sonicated with a probe sonicator (MSE Ultrasonic Disintegrator, London, UK) for $15 \mathrm{~min}$ at $150 \mathrm{~W}$ (Volkovova et al. 2015) to prepare a stock solution. During sonication, the flask was cooled with ice in order to prevent the dispersion from overheating. To reach the final experimental concentration, the stock suspension of nanoparticles was diluted with the cell culture medium and vortexed again immediately before cell treatment.

Physico-chemical characteristics, average particle size, hydrodynamic size distribution, degree of aggregation, and zeta potential of tested nanoparticles at concentration $1 \mathrm{mg} \cdot \mathrm{ml}^{-1}$ were measured at $25^{\circ} \mathrm{C}$ by dynamic light scattering (DLS) (Malvern Instrument Zetasizer Nano, Malvern, United Kingdom). DLS analysis revealed that both AgNPs and TiO2NPs solutions were polydisperse suspensions with three populations of particles, for AgNPs: $608 \mathrm{~nm}$ (78.45\%), $172 \mathrm{~nm}(11.4 \%)$ and $5282 \mathrm{~nm}(10.15 \%)$, with average diameter of $722 \mathrm{~nm}$; and for TiO2NPs: $339 \mathrm{~nm}$ (96.65\%), $4943 \mathrm{~nm}$ (5.45\%) and $72 \mathrm{~nm}$ (0.9\%), with an average diameter of $310 \mathrm{~nm}$. The AgNPs and TiO2NPs were negatively charged with a zeta potential of -13.73 and $-15.5 \mathrm{mV}$, respectively. Polydispersity index (PDI) of AgNPs and TiO2NPs was 0.676 and 0.357 , respectively.

Preparation, culture, and processing of ovarian cells. Granulosa cells were isolated from the ovaries of non-cycling, 180-day-old prepubertal gilts, collected at a local abattoir, and cultured as previously described (Tarko et al. 2018, 2019). Isolated granulosa cells $\left(10^{6}\right.$ cells $/ \mathrm{ml}$ medium $)$ were cultured in 24-well plate wells (1 ml/well) or 12-well chamberslide $(0.2 \mathrm{ml} /$ well) (both from Nunc International, Naperville, IL, USA) in Dulbecco's modified Eagle's medium (DMEM)/F12 1:1 medium (BioWhittakerTM, Verviers, Belgium), supplemented with $10 \%$ fetal calf serum (BioWhittakerTM), and a $1 \%$ antibiotic-antimycotic solution (Sigma-Aldrich) for 3 days up to the establishment of a $60-70 \%$ confluent cell monolayer. Thereafter, the culture medium was replaced with fresh medium, with and without sonicated AgNPs and TiO2NPs described above at doses $\mathrm{v}(0.1,1,10$ or $100 \mu \mathrm{g} / \mathrm{ml})$ in presence or absence of resveratrol (Changsha Sunfull Bio-tech. Co, Hunan, China), diosgenin (AppliChem GmbH, Darmstadt, Germany) and quercetin (AppliChem $\mathrm{GmbH}$ ) (all at $10 \mu \mathrm{g} / \mathrm{ml})$. These plant molecules were first dissolved in $50 \mu \mathrm{l}$ of dimethyl sulfoxide (DMSO) (AppliChem $\mathrm{GmbH}$ ) to reach stock solutions of $1 \mathrm{mg} / \mathrm{ml}$ for each plant extract. Thereafter, these stock solutions were dissolved in culture medium immediately before their addition to the granulosa cells, such that the final concentration of DMSO did not exceed $0.001 \%$. Previous studies did not reveal substantial effects of $0.001 \%$ DMSO on ovarian cell function and viability (data not shown). The chosen dose of plant molecules corresponds to their level and metabolism in the ovary (Gao et al. 2012; van Duursen 2017; Bodis et al. 2019) and the effective doses used in previous in vivo experiments (Santini et al. 2009; Atlante et al. 2010; Ortega et al. 2012; Almeida et al. 2015; Tarko et al. 2018, 2019; Wu et al. 2019; Jozkowiak et al. 2020). After 2 days of culture, the number of cells was determined using hemocytometer, and the number of nanoparticle aggregates/clusters within the cells was counted under light microscope at magnification $\times 400$. The medium was subjected to progesterone analysis by ELISA.

ELISA. Concentrations of progesterone were determined in $25 \mu \mathrm{l}$ aliquots of the incubation medium using ELISA kit according to the manufacturer's instructions (LDN Immunoassays and Services, Nodhorn, Germany). The cross-reactivity of antiserum against progesterone was $\leq 1.1 \%$ with 11 -desoxycorticosterone, $\leq 0.35 \%$ with pregnenolone, $\leq 0.30 \%$ with $17 \alpha$-hydroxyprogesterone, $\leq 0.20 \%$ with corticosterone, $<0.10 \%$ with estriol, $17 \beta$-estradiol, testosterone, cortisone, and 11-desoxycortisol, and $<0.02 \%$ with DHEA-S and cortisol. The sensitivity of the assay was $0.045 \mathrm{ng} / \mathrm{ml}$. Intra- and inter-assay coefficients of variation did not exceed $5.40 \%$ and $5.59 \%$, respectively. This ELISA was validated for the culture medium samples by dilution tests.

Statistical analysis. Each experiment was repeated three times using ovaries from different animals (10-15 gilts per experiment). Each experimental group was represented by four plate wells. Using ELISA, blank control values were subtracted from the value determined in the cell-conditioned serum-supplemented medium to exclude any non-specific background (less than $10 \%$ of the total values). Secretion rates were calculated per $10^{6}$ cells/day. For evaluation of nanoparticle accumulation, at least 500 cells per group were inspected. If the number of nanoparticles per cell was more than 100, the individual nanoparticles were not recognizable, and their number was indicated as ">100". Differences between groups were evaluated using the Shapiro-Wilk's normality and Student's t-tests, and ANOVA followed by Tukey's test with Sigma Plot 11.0 (Systat Software, GmbH, Erkhart, Germany). Values were presented as the mean \pm SEM. Differences were compared for statistical significance at $\mathrm{p}$ levels less than $0.05(\mathrm{p}<0.05)$. 


\section{Results}

During the experiment, cells created a monolayer (Figure 1) and produced a substantial amount of progesterone (Figure 2). The addition of AgNPs and TiO2NPs to ovarian granulosa cell culture resulted in accumulation of both nanoparticles within the cells (Figure 1). Addition of both nanoparticles at doses 1 and $10 \mu \mathrm{g} / \mathrm{ml}$ induced their accumulation in a dose-dependent manner (Table 1). Addition of AgNPs at the highest $(100 \mu \mathrm{g} / \mathrm{ml})$ dose resulted in lysis and disappearance of cell monolayer, whilst cells after culture with TiO2NPs at dose $100 \mu \mathrm{g} / \mathrm{ml}$ and with $\mathrm{TiO} 2 \mathrm{NPs}$ at $10 \mu \mathrm{g} / \mathrm{ml}+$ resveratrol contained so much nanoparticles and their aggregates $(>100)$ that the clusters of nanoparticles were impossible to count (Table 1). Nanoparticles were accumulated in cells cultured with nanoparticles both with and without plant molecules. Nevertheless, cells cultured with either resveratrol, diosgenin or quercetin accumulated significantly more AgNPs and TiO2NPs than the corresponding groups of cells cultured without these plant molecules (Table 1).

Progesterone release was diminished after addition of both AgNPs (at all doses added) and TiO2NPs (at doses 0.1 and $1 \mu \mathrm{g} / \mathrm{ml}$ ) (Figure 2). All tested plant molecules substantially inhibited progesterone output (Figure 2, see AgNPs and TiO2NPs at $0 \mu \mathrm{g} / \mathrm{ml}$ ), too. Moreover, in the presence of resveratrol (Figure 2A) and diosgenin (Figure 2B), AgNPs and TiO2NPs did not suppress progesterone secretion. On the contrary, quercetin did not modify substantially the inhibitory action of either AgNPs or TiO2NPs on progesterone release (Figure 2C).

\section{Discussion}

In the present experiments, both studied nanoparticles reduced progesterone release by ovarian cells. Moreover, addition of AgNPs at high dose destroyed the cell monolayer, what indicates AgNPs-induced reduction in cell attachment and viability. These observations confirm the previous evidence of toxicity of AgNPs (Kim et al. 2004; Han et al. 2016; Brohi et al. 2017) and TiO2NPs (Hou et al. 2009; Di Virgilio et al. 2010; Gao et al. 2012; Zhao et al. 2013; Hong and Wang 2018) on female reproductive system. Furthermore, the present observations are the first demonstration of ability of AgNPs and TiO2NPs to enter the ovarian cells from the surrounding medium. This supports the previous evidence of direct effect of AgNPs (Han et al. 2016; De Matteis et al. 2018) and TiO2NPs (Hou et al. 2009; Di Virgilio et al. 2010) on ovarian cells.

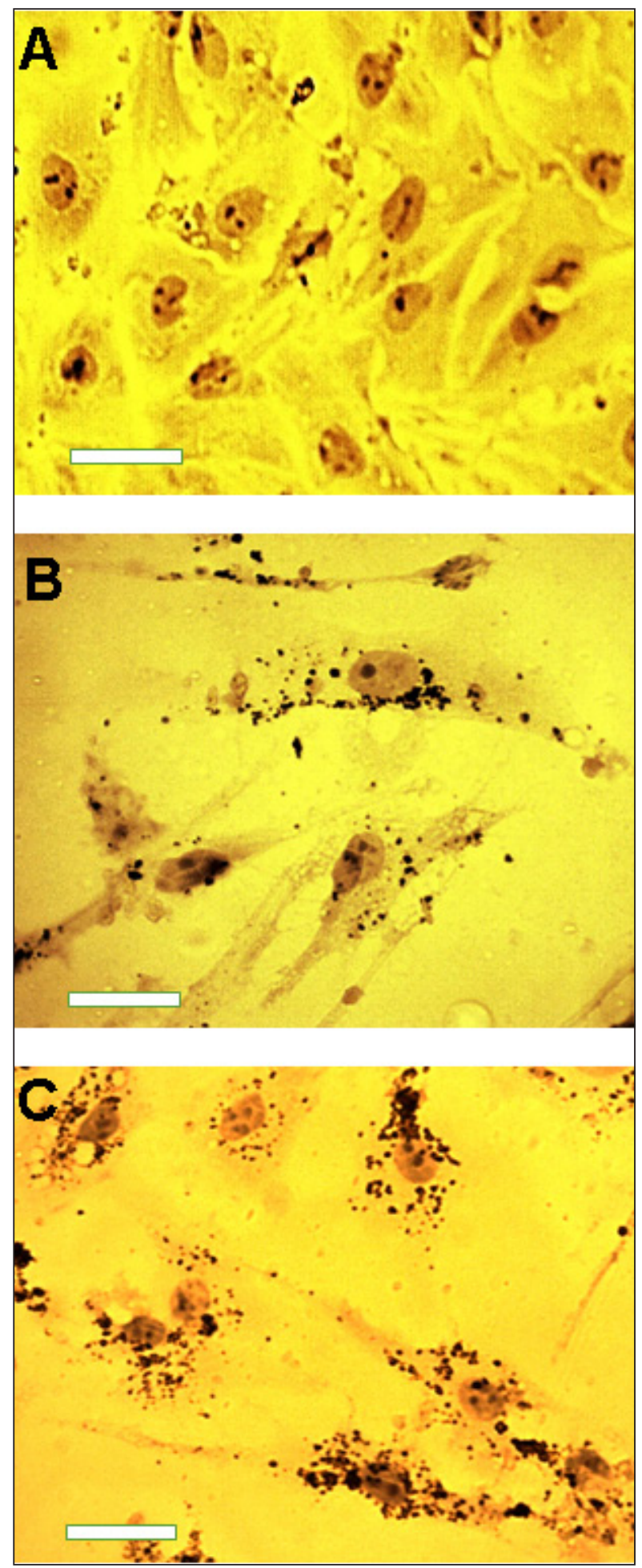

Figure 1. Cultured porcine ovarian granulosa cells (A) not containing nanoparticles (control cells cultured without nanoparticles), (B) containing silver nanoparticles and their aggregates (cells cultured with silver nanoparticles at dose $1 \mu \mathrm{g} / \mathrm{ml}$ ) and (C) containing titania nanoparticles (cells cultured with titanium dioxide nanoparticles at dose $10 \mu \mathrm{g} / \mathrm{ml}$ ). The scale bars indicate $10 \mu \mathrm{m}$. 

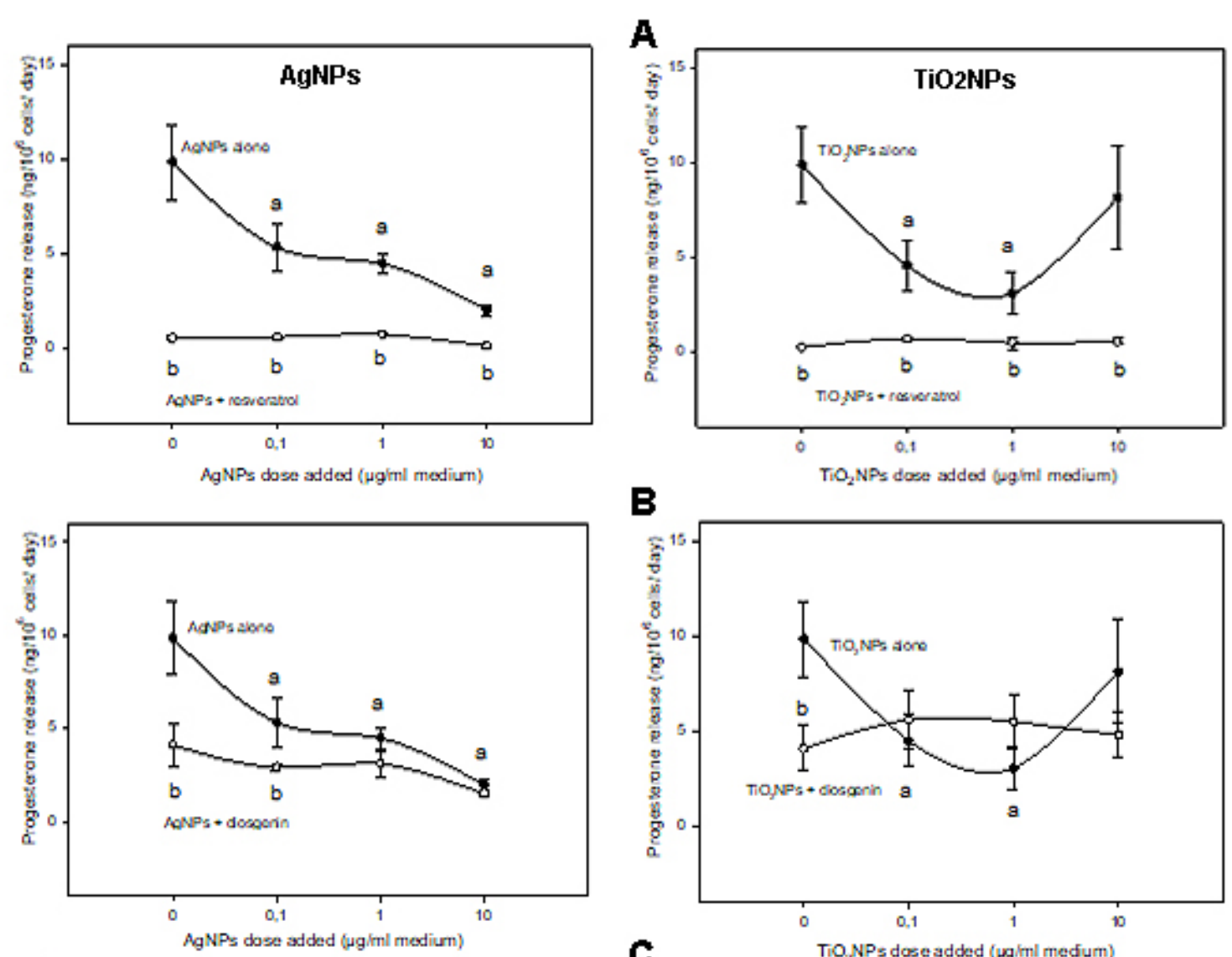

3
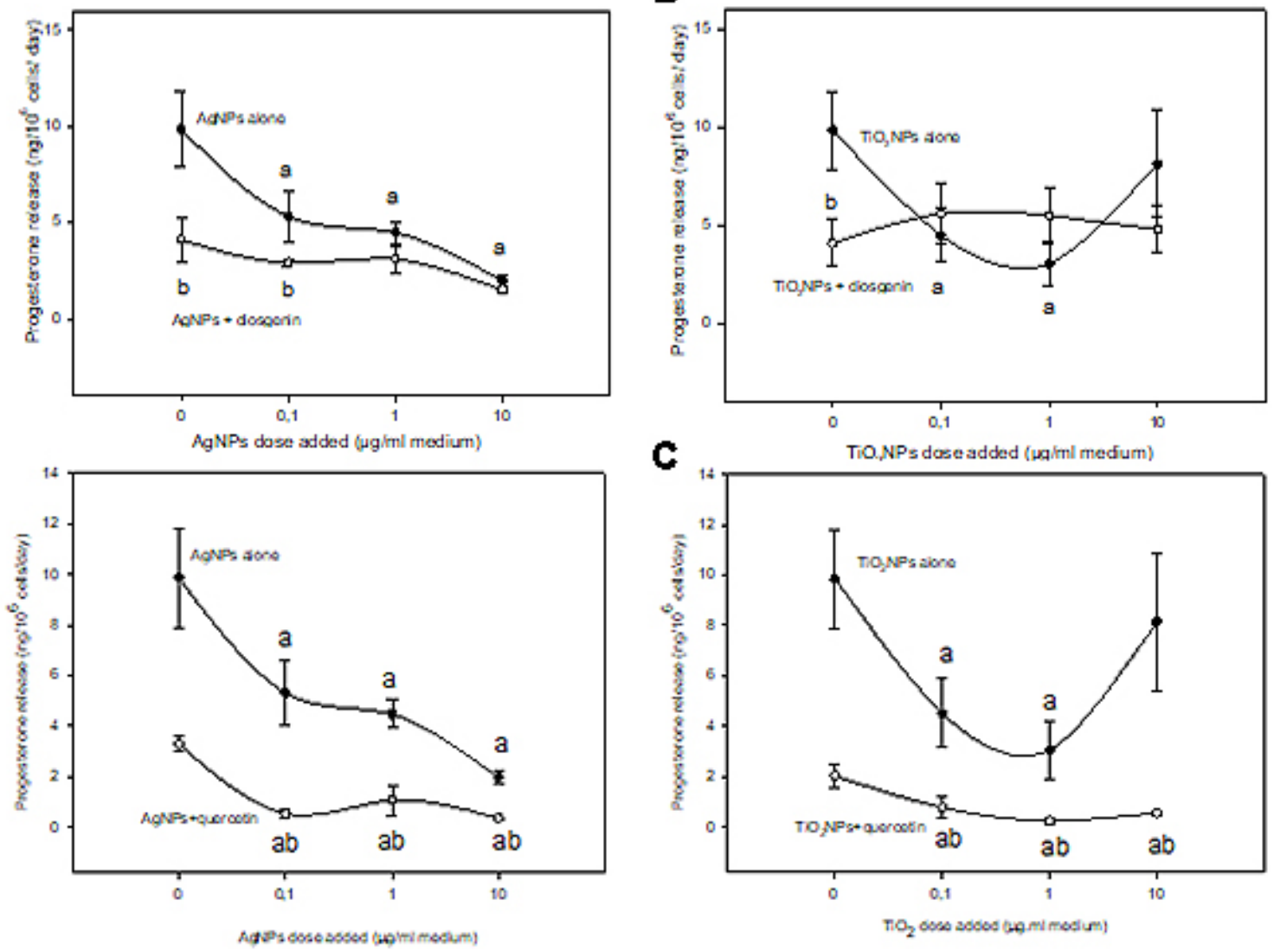

Figure 2. Progesterone release by porcine ovarian granulosa cells cultured with and without silver nanoparticles (AgNPs, left) and titanium dioxide nanoparticles (TiO2NPs, rights) alone or in the presence of plant flavonoids resveratrol (A), diosgenin (B) and quercetin $(\mathbf{C})$. Values are presented as a mean \pm SEM. a - effect of nanoparticles: a significant difference $(\mathrm{p}<0.05)$ between cells cultured without and with nanoparticles; $b$ - effect of plant flavonoids: a significant difference $(p<0.05)$ between corresponding groups of cells cultured with and without plant flavonoid.

The performed experiments confirm the previous reports concerning the ability of plant isoflavones resveratrol (Ortega et al. 2012; Banu et al. 2016; Jozkowiak et al. 2020), diosgenin (van Duursen
2017; Sirotkin et al. 2019), and quercetin (Santini et al. 2009; Tarko et al. 2018, 2019) to reduce ovarian cell progesterone secretion directly. Furthermore, the obtained results are the first evidence for ability 
of plant isoflavones to affect nanoparticles uptake. It can be hypothesized that effect of isoflavones on the progesterone release observed in the present experiments was due to their ability to promote the accumulation of the toxic nanoparticles - inhibitors of progesterone secretion.

In the present studies, resveratrol and diosgenin, but not quercetin, were able to fully eliminate the inhibitory action of both AgNPs and TiO2NPs on ovarian cell progesterone release. On the other hand, none of the tested flavonoids prevented AgNPinduced lysis of cell monolayer. The present results show that some (but not all) suppressive action of AgNPs and TiO2NPs on ovarian cells can be mitigated by resveratrol and diosgenin or a functional food containing these polyphenols.

Understanding the mechanisms of this protective action of resveratrol and diosgenin against adverse effects of nanoparticles on ovarian progesterone release requires further studies. It can not be excluded that these phytoestrogens can interfere with steroid hormone receptors (Sirotkin and Harrath 2014; Rietjens et al. 2017) and make them insensitive to nanoparticle action. Furthermore, the toxic effect of many nanoparticles (Brohi et al. 2017), including AgNPs (Flores-Lopez et al. 2019) and TiO2NPs (Gao et al. 2012; Grande and Tucci 2016), can be due to their ability to induce oxidative stress, whilst the protective action of plant isoflavones could be a consequence of their anti-oxidant properties (Atlante et al. 2010; Jungbauer and Medjakovic 2014). Finally, the ability of all tested plant isoflavones to affect uptake of both AgNPs and TiO2NPs suggests their effect on the cell membrane permeability. The ability of a number of plant phytoestrogens to alter characteristics and permeability of membranes in non-ovarian cells have been reported (Feranchak et al. 2003; Atlante et al. 2010; Brohi et al. 2017), but the present observations are the first indications of such flavonoids action on ovarian cells. This ability cannot, however, explain the reduction in AgNPs and $\mathrm{TiO} 2 \mathrm{NPs}$ effects on progesterone release in the presence of resveratrol and diosgenin because these flavonoids did not reduce, but rather promoted AgNPs and $\mathrm{TiO} 2 \mathrm{NPs}$ uptake by ovarian cells.

The present observations enable to outline some suggestions concerning the practical application of nanoparticles and plant molecules. The nanoparticle-induced reduction in ovarian hormone output confirm that exposition to both AgNPs and TiO2NPs may pose a threat to female reproductive processes. The destruction of the cell monolayer after addition of AgNPs, but not of TiO2NPs, indicates that AgNPs are more toxic than TiO2NPs. The ability of plant molecules to suppress the progesterone release shows that the consumption of food or medical plants containing resveratrol, diosgenin, and quercetin can also suppress the release of this

Table 1

Accumulation of nanoparticles (NPs) in porcine ovarian granulosa cells cultured with and without silver nanoparticles (AgNPs) and titanium dioxide nanoparticles (TiO2NPs) alone and in presence of plant flavonoids resveratrol, diosgenin and quercetin.

\begin{tabular}{|c|c|c|c|c|}
\hline \multirow{2}{*}{$\begin{array}{l}\text { NPs concentration } \\
(\mu \mathrm{g} / \mathrm{ml})\end{array}$} & \multirow[b]{2}{*}{ AgNPs alone } & \multicolumn{3}{|c|}{ AgNPs and plant flavonoid } \\
\hline & & $\begin{array}{l}\text { Resveratrol } \\
(10 \mu \mathrm{g} / \mathrm{ml})\end{array}$ & $\begin{array}{l}\text { Diosgenin } \\
(1 \mu \mathrm{g} / \mathrm{ml})\end{array}$ & $\begin{array}{l}\text { Quercetin } \\
(10 \mu \mathrm{g} / \mathrm{ml})\end{array}$ \\
\hline 0 & $0.00 \pm 0.00$ & $0.00 \pm 0.00$ & $0.00 \pm 0.00$ & $0.00 \pm 0.00$ \\
\hline 1 & $8.65 \pm 0.56 a$ & $15.36 \pm 1.76 \mathrm{ab}$ & $15.83 \pm 2.00 \mathrm{ab}$ & $5.94 \pm 0.62 \mathrm{ab}$ \\
\hline 10 & $19.42 \pm 0.70 \mathrm{a}$ & $18.58 \pm 1.49 \mathrm{a}$ & $25.03 \pm 7.57 \mathrm{ab}$ & $26.58 \pm 1.81 \mathrm{ab}$ \\
\hline 100 & No cells & No cells & No cells & No cells \\
\hline \multirow{2}{*}{$\begin{array}{l}\text { NPs concentration } \\
(\mu \mathrm{g} / \mathrm{ml})\end{array}$} & \multirow[b]{2}{*}{ TiO2NPs alone } & \multicolumn{3}{|c|}{ TiO2NPs and plant flavonoid } \\
\hline & & $\begin{array}{c}\text { Resveratrol } \\
(10 \mu \mathrm{g} / \mathrm{ml})\end{array}$ & $\begin{array}{c}\text { Diosgenin } \\
(1 \mu \mathrm{g} / \mathrm{ml})\end{array}$ & $\begin{array}{l}\text { Quercetin } \\
(10 \mu \mathrm{g} / \mathrm{ml})\end{array}$ \\
\hline 0 & $0.00 \pm 0.00$ & $0.00 \pm 0.00$ & $0.00 \pm 0.00$ & $0.00 \pm 0.00$ \\
\hline 1 & $9.62 \pm 0.57 \mathrm{a}$ & $19.24 \pm 0.89 \mathrm{ab}$ & $8.54 \pm 0.88 \mathrm{a}$ & $17.40 \pm 0.98 \mathrm{ab}$ \\
\hline 10 & $45.79 \pm 2.21 \mathrm{a}$ & $>100$ & $65.17 \pm 5.77 \mathrm{ab}$ & $39.83 \pm 1.90 \mathrm{ab}$ \\
\hline 100 & $>100$ & $>100$ & $>100$ & $>100$ \\
\hline
\end{tabular}

The values represent number of NPs and aggregates of NPs per cell (means \pm SEM). a - effect of nanoparticle: significant difference $(p<0.05)$ between cells cultured without and with nanoparticles; $b$ - effect of plant flavonoid: significant difference $(p<0.05)$ between corresponding groups of cells cultured with or without plant flavonoid. 
hormone and hormone-dependent functions of ovarian cells (Sirotkin 2014). Moreover, resveratrol and diosgenin (but not quercetin) could be promising natural protectors against suppressive action of both AgNPs and TiO2NPs on progesterone release and probably on progesterone-dependent ovarian processes (Sirotkin 2014). On the other hand, none of the tested plant molecules was able to prevent the destructive effect of AgNPs on the ovarian cell monolayer.

The details of nanoparticle and phytoflavonoid actions, their functional interrelationships, and possibilities of their application are worth future studies. Nevertheless, the present observations (1) demonstrate accumulation of AgNPs, and TiO2NPs in ovarian cells, (2) confirm the toxic influence of AgNPs, and TiO2NPs on these cells, (3) confirm the influence of plant polyphenols/phytoestrogens resveratrol, diosgenin, and quercetin on the ovarian steroidogenesis, (4) show the ability of these flavonoids to increase the accumulation of AgNPs, and TiO2NPs, the ability of resveratrol and diosgenin to reduce the suppressive effect of AgNPs, and TiO2NPs on ovarian progesterone release. The adverse effect of AgNPs and TiO2NPs on ovarian functions should be taken into account before their application, but these adverse effects could be mitigated by plant polyphenols resveratrol and diosgenin.

\section{Acknowledgements}

This work was supported by the Slovak Research and Development Agency (projects no. APVV-150296) and by the Scientific Grant Agency of the Ministry of Education, Science, and Sport of Slovak Republic (project VEGA 13-ENV1321-02).

\section{References}

Almeida IM, Rodrigues F, Sarmento B, Alves RC, Oliveira MB. Isoflavones in food supplements: chemical profile, label accordance and permeability study in Caco-2 cells. Food Funct 6, 938-946, 2015.

Atlante A, Bobba A, Paventi G, Pizzuto R, Passarella S. Genistein and daidzein prevent low potassium-dependent apoptosis of cerebellar granule cells. Biochem Pharmacol 79, 758-767, 2010.

Banu SK, Stanley JA, Sivakumar KK, Arosh JA, Burghardt RC. Resveratrol protects the ovary against chromium-toxicity by enhancing endogenous antioxidant enzymes and inhibiting metabolic clearance of estradiol. Toxicol Appl Pharmacol 303, 65-78, 2016.

Baranowska-Wojcik E, Szwajgier D, Oleszczuk P, Winiarska-Mieczan A. Effects of titanium dioxide nanoparticles exposure on human health - a review. Biol Trace Elem Res 193, 118-129, 2020.

Beazley KE, Nurminskaya M. Effects of dietary quercetin on female fertility in mice: implication of transglutaminase 2. Reprod Fertil Dev 28, 974-981, 2016.

Bodis J, Sulyok E, Koszegi T, Godony K, Premusz V, Varnagy A. Serum and follicular fluid levels of sirtuin 1, sirtuin 6 , and resveratrol in women undergoing in vitro fertilization: an observational, clinical study. J Int Med Res 47, 772-782, 2019.

Brohi RD, Wang L, Talpur HS, Wu D, Khan FA, Bhattarai D, Rehman ZU, Farmanullah F, Huo LJ. Toxicity of nanoparticles on the reproductive system in animal models: a review. Front Pharmacol 8, 606, 2017.

De Matteis V, Cascione M, Toma CC, Leporatti S. Silver nanoparticles: synthetic routes, in vitro toxicity and theranostic applications for cancer disease. Nanomaterials (Basel) 8, 319, 2018.

Di Virgilio AL, Reigosa M, Arnal PM, Fernandez Lorenzo de Mele M. Comparative study of the cytotoxic and genotoxic effects of titanium oxide and aluminium oxide nanoparticles in Chinese hamster ovary (CHO-K1) cells. J Hazard Mater 177, 711-718, 2010.

Feranchak AP, Kilic G, Wojtaszek PA, Qadri I, Fitz JG. Volume-sensitive tyrosine kinases regulate liver cell volume through effects on vesicular trafficking and membrane Na+ permeability. J Biol Chem 278, 44632-44638, 2003.

Flores-Lopez LZ, Espinoza-Gomez H, Somanathan R. Silver nanoparticles: Electron transfer, reactive oxygen species, oxidative stress, beneficial and toxicological effects. Mini review. J Appl Toxicol 39, 16-26, 2019.

Gao G, Ze Y, Li B, Zhao X, Zhang T, Sheng L, Hu R, Gui S, Sang X, Sun Q, Cheng J, Cheng Z, Wang L, Tang M, Hong F. Ovarian dysfunction and gene-expressed characteristics of female mice caused by long-term exposure to titanium dioxide nanoparticles. J. Hazard. Mater 243, 19-27, 2012.

Grande F, Tucci P. Titanium dioxide nanoparticles: a risk for human health? Mini Rev Med Chem 16, 762-769, 2016.

Han JW, Jeong JK, Gurunathan S, Choi YJ, Das J, Kwon DN, Cho SG, Park C, Seo HG, Park JK, Kim JH. Male-and female-derived somatic and germ cell-specific toxicity of silver nanoparticles in mouse. Nanotoxicology 10, 361-373, 2016. 
Hill EK, Li J. Current and future prospects for nanotechnology in animal production. J Animal Sci Biotechnol 8, 26, 2017.

Hong F, Wang L. Nanosized titanium dioxide-induced premature ovarian failure is associated with abnormalities in serum parameters in female mice. Int J Nanomedicine 13, 2543-2549, 2018.

Hou J, Wan XY, Wang F, Xu GF, Liu Z [Effects of titanium dioxide nanoparticles on development and maturation of rat preantral follicle in vitro]. Acad J Second Mil Med Univ 30, 869-873, 2009.

Jahan S, Abid A, Khalid S, Afsar T, Qurat-Ul-Ain, Shaheen G, Almajwal A, Razak S. Therapeutic potentials of Quercetin in management of polycystic ovarian syndrome using Letrozole induced rat model: a histological and a biochemical study. J Ovarian Res 11, 26, 2018.

Jozkowiak M, Hutchings G, Jankowski M, Kulcenty K, Mozdziak P, Kempisty B, Spaczynski RZ, Piotrowska-Kempisty $\mathrm{H}$. The stemness of human ovarian granulosa cells and the role of resveratrol in the differentiation of MSCs-A review based on cellular and molecular knowledge. Cells 9, 1418, 2020.

Jungbauer A, Medjakovic S. Phytoestrogens and the metabolic syndrome. J Steroid Biochem Mol Biol 139, 277-289, 2014.

Kim S, Lim YT, Soltesz EG, De Grand AM, Lee J, Nakayama A, Parker JA, Mihaljevic T, Laurence RG, Dor DM, Cohn LH, Bawendi MG, Frangioni JV. Near-infrared fluorescent type II quantum dots for sentinel lymph node mapping. Nat Biotechnol 22, 93-97, 2004.

Li N, Sun C, Zhou B, Xing H, Ma D, Chen G, Weng D. Low concentration of quercetin antagonizes the cytotoxic effects of anti-neoplastic drugs in ovarian cancer. PLoS One 9, e100314, 2014.

Liu Y, Wang YL, He SW, Chen MH, Zhang Z, Fu XP, Fu BB, Liao BQ, Lin YH, Qi ZQ, Wang HL. Protective effects of resveratrol against mancozeb induced apoptosis damage in mouse oocytes. Oncotarget 8, 6233-6245, 2017.

Mikhailov OV, Mikhailova EO. Elemental Silver nanoparticles: biosynthesis and bio applications. Materials (Basel) 12, 3177, 2019.

Nawaz W, Zhou Z, Deng S, Ma X, Ma X, Li C, Shu X. Therapeutic versatility of resveratrol derivatives. Nutrients 9 , 1188, 2017.

Ortega I, Villanueva JA, Wong DH, Cress AB, Sokalska A, Stanley SD, Duleba AJ. Resveratrol reduces steroidogenesis in rat ovarian theca-interstitial cells: the role of inhibition of Akt/PKB signaling pathway. Endocrinology 153, 4019-4029, 2012.

Ozatik FY, Ozatik O, Yigitaslan S, Kaygisiz B, Erol K. Do resveratrol and dehydroepiandrosterone increase diminished ovarian reserve? Eurasian J Med 52, 6-11, 2020.

Podolak I, Galanty A, Sobolewska D. Saponins as cytotoxic agents: a review. Phytochem Rev 9, 425-474, 2010.

Rietjens IMCM, Louisse J, Beekmann K. The potential health effects of dietary phytoestrogens. Br J Pharmacol 174, 1263-1280, 2017.

Said RS, El-Demerdash E, Nada AS, Kamal MM. Resveratrol inhibits inflammatory signaling implicated in ionizing radiation-induced premature ovarian failure through antagonistic crosstalk between silencing information regulator 1 (SIRT1) and poly(ADP-ribose) polymerase 1 (PARP-1). Biochem Pharmacol 103, 140-150, 2016.

Said RS, Mantawy EM, El-Demerdash E. Mechanistic perspective of protective effects of resveratrol against cisplatininduced ovarian injury in rats: emphasis on anti-inflammatory and anti-apoptotic effects. Naunyn Schmiedebergs Arch Pharmacol 392, 1225-1238, 2019.

Santini SE, Basini G, Bussolati S, Grasselli F. The phytoestrogen quercetin impairs steroidogenesis and angiogenesis in swine granulosa cells in vitro. J Biomed Biotechnol 2009, 419891, 2009.

Sirotkin AV. Regulators of ovarian functions, second ed., Nova Science Publishers, Inc New York, 2014.

Sirotkin AV, Harrath AH. Phytoestrogens and their effects. Eur J Pharmacol 741, 230-236, 2014.

Sirotkin AV, Alexa R, Alwasel S, Harrath AH. The phytoestrogen, diosgenin, directly stimulates ovarian cell functions in two farm animal species. Domest Anim Endocrinol 69, 35-41, 2019.

Tarko A, Stochmalova A, Hrabovszka S, Vachanova A, Harrath AH, Alwasel S, Grossman R, Sirotkin AV. Can xylene and quercetin directly affect basic ovarian cell functions? Res Vet Sci 119, 308-312, 2018.

Tarko A, Stochmalova A, Jedlickova K, Hrabovszka S, Vachanova A, Harrath AH, Alwasel S, Alrezaki A, Kotwica J, Balazi A, Sirotkin AV. Effects of benzene, quercetin, and their combination on porcine ovarian cell proliferation, apoptosis, and hormone release. Arch Anim Breed 62, 345-351, 2019.

van Duursen MBM. Modulation of estrogen synthesis and metabolism by phytoestrogens in vitro and the implications for women's health. Toxicol Res (Camb) 6, 772-794, 2017.

Volkovova K, Handy RD, Staruchova M, Tulinska J, Kebis A, Pribojova J, Ulicna O, Kucharska J, Dusinska M. Health effects of selected nanoparticles in vivo: liver function and hepatotoxicity following intravenous injection of titanium dioxide and $\mathrm{Na}$-oleate-coated iron oxide nanoparticles in rodents. Nanotoxicology 9 (Suppl 1), 95-105, 2015. 
Wu M, Ma L, Xue L, Ye W, Lu Z, Li X, Jin Y, Qin X, Chen D, Tang W, Chen Y, Hong Z, Zhang J, Luo A, Wang S. Resveratrol alleviates chemotherapy-induced oogonial stem cell apoptosis and ovarian aging in mice. Aging (Albany NY) 11, 1030-1044, 2019.

Zhang J, Chen Q, Du D, Wu T, Wen J, Wu M, Zhang Y, Yan W, Zhou S, Li Y, Jin Y, Luo A, Wang S. Can ovarian aging be delayed by pharmacological strategies? Aging (Albany NY) 11, 817-832, 2019.

Zhao X, Ze Y, Gao G, Sang X, Li B, Gui S, Sheng L, Sun Q, Cheng J, Cheng Z, Hu R, Wang L, Hong F. Nanosized TiO2induced reproductive system dysfunction and its mechanism in female mice. PLoS One 8, e59378, 2013. 